\title{
Acalypha wilkesiana 'inferno' hydroethanolic leaf extract has protective effect on carbon tetrachloride-induced subacute toxicity in animals
}

\author{
Christopher Larbie ${ }^{1, * \odot}$, Benjamin O. Emikpe $^{2 \odot}$, Ademola A. Oyagbemi $^{3 \odot}$, Ruby A. Nyarko ${ }^{4 \odot}$, \\ Theophilus A. Jarikre ${ }^{5}{ }^{\circledR}$, Clement O. Adjei ${ }^{1}$, Emmanuel B. Aseidu ${ }^{1}$
}



Use your smartphone to scan this QR code and download this article

${ }^{1}$ Department of Biochemistry and Biotechnology, Kwame Nkrumah University of Science and Technology, Kumasi-Ghana

${ }^{2}$ Department of Pathobiology, School of Veterinary Medicine, KNUST, Ghana

${ }^{3}$ Department of Veterinary Physiology and Biochemistry, University of Ibadan, Nigeria

${ }^{4}$ Department of Theoretical and Applied Biology, KNUST, Ghana

${ }^{5}$ Department of Veterinary Pathology, University of Ibadan, Nigeria

Correspondence

Christopher Larbie, Department of Biochemistry and Biotechnology, Kwame Nkrumah University of Science and Technology, Kumasi-Ghana

Email: clarbie.cos@knust.edu.gh

History

- Received: Feb 19, 2020

- Accepted: Apr 30, 2020

- Published: May 25, 2020

DOI : 10.15419/bmrat.v7i5.605

\section{Check for updates}

Copyright

(c) Biomedpress. This is an openaccess article distributed under the terms of the Creative Commons Attribution 4.0 International license.

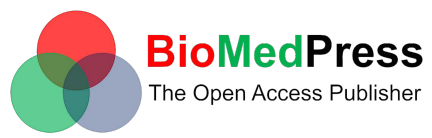

\begin{abstract}
Introduction: Liver fibrosis is one of the most common clinical manifestations of hepatic diseases However, though many synthetic drugs exist for the treatment and prevention of liver diseases, liver injuries still persist. The present study, therefore, sought to investigate the subacute protective effects of Acalphya wilkesiana against carbon tetrachloride $\left(\mathrm{CCl}_{4}\right)$-induced toxicity in animals. Methodology: Liver injury was induced in experimental animals by administering $\mathrm{CCl}_{4}(1: 1 \mathrm{v} / \mathrm{V}$ in olive oil, intraperitoneally (i.p.), twice weekly for 8 weeks) after pre-treatment with extract of $A$. wilkesiana (AWE). AWE (250 mg/kg) and Silymarin $(120 \mathrm{mg} / \mathrm{kg}$ ) were administered orally (daily for 8 weeks). The hepatoprotective effect was studied by assaying the activity of liver enzymes, such as alanine aminotransferase (ALT), aspartate aminotransferase (AST), alkaline phosphatase (ALP), and alpha-fetoprotein. The effect of the treatments on liver prooxidants (e.g. malondialdehyde [MDA]) and antioxidants (e.g. superoxide dismutase [SOD], reduced glutathione [GSH], glutathione peroxidase [GPX], and glutathione transferase [GST]), as well as inflammatory cytokines (e.g. interleukin [IL]-17, IL-23, nuclear factor kappa beta [NF-kB], and cycloxygenase-1 [COX-1]) and the histology of the liver were also examined. Results: The activity of liver function biomarkers changed significantly upon $\mathrm{CCl}_{4}$ administration; increases in $\mathrm{ALT}$, total and direct bilirubin, and some fibrosis indices (e.g. alpha-fetoprotein and APRI $[p<0.05-0.001$, compared with normal]) were observed. $\mathrm{Co}$-administration of AWE with $\mathrm{CCl}_{4}$ restored these to normal levels. The intensity of structural alterations revealed that the AWE treatment has protective potential against subacute liver injury. AWE treatment also reduced the expression of IL-17, 1L-23, NF-kB and COX-1, underscoring its antiinflammatory properties. Conclusion: The results of the current study generally suggest that hydroethanolic leaf extracts of $A$. wilkesiana inferno possess some subacute protective activity by improving liver function and inhibition of inflammation, and could be developed as a potent antifibrotic agent.
\end{abstract}

Key words: Acalypha wilkesiana inferno, carbon tetrachloride, hepatoprotective effect, medicinal plants, interleukins

\section{INTRODUCTION}

The liver serves as the main hub for important activities such as metabolism, secretion, detoxification and storage. When any of these functions is distorted, liver damage is said to have occurred ${ }^{1}$. Although many synthetic drugs exist for the treatment and prevention of ailments, even for liver diseases, liver injuries still persist $^{2}$. According to the WHO, nearly 2.4 million deaths are associated with liver injury and damage annually ${ }^{1}$.

Liver fibrosis is one of the most common clinical manifestations of hepatic diseases. It is the excessive amassing of the extracellular protein matrix, including collagen, elastin, fibronectin, laminin and proteoglycans in the liver ${ }^{3}$. These proteins are generated from activated hepatic stellate cells (HSCs). Activation of HSCs is associated with increased mRNA expression of collagen, tumor growth factor- $\beta$ (TGF$\beta$ ), and alpha-smooth muscle actin ( $\alpha$-SMA $)^{4}$. Liver fibrosis is caused by chronic hepatic injury and is associated with inflammation-associated conditions, such as alcoholic and non-alcoholic steatohepatitis, viral hepatitis, and even autoimmune diseases ${ }^{3}$. Several anti-fibrotic therapies, therefore, target either the activated HSCs or are anti-inflammatory in action ${ }^{3}$. Meanwhile, cirrhosis is the end stage of several liver diseases and is an irreversible form of liver fibrosis. Together with liver fibrosis, cirrhosis is responsible for several mortalities and morbidities worldwide, especially in developing countries ${ }^{4}$. 
Hepatotoxins are agents that cause liver damage. There are several examples of hepatotoxins, and these are grouped into intrinsic and idiosyncratic hepatotoxins. Some common hepatotoxins include ethanol, carbon tetrachloride, and acetaminophen, among others. Agents that protect the liver from deleterious effects of hepatotoxins are said to be hepatoprotective ${ }^{1}$. Carbon tetrachloride $\left(\mathrm{CCl}_{4}\right)$ is a well-known intrinsic hepatotoxin, first reported as a cause of liver injury in $1936^{5}$. It is widely used for the study of liver inflammation, fibrosis and cirrhosis. It belongs to a group of hepatotoxins which needs to be metabolized by the mixed-function oxidases in the liver. Once metabolized by cytochrome $\mathrm{P} 450$ oxidases, $\mathrm{CCl}_{4}$ generates trichloromethyl radical $\left(\mathrm{CCl}_{3} \mathrm{O} \cdot\right)$, a very reactive free radical which results in primary and secondary bond formation (a covalent bond formation with DNA, proteins, lipids and carbohydrates, and generation of free radicals, lipid peroxidation, etc., respectively) ${ }^{6}$. Thus, $\mathrm{CCl}_{3} \mathrm{O}$ is responsible for the several toxic effects following carbon tetrachloride administration.

The numerous side effects of synthetic drugs spur the growing interest of medical researchers in the evaluation of traditional herbal formulations ${ }^{2}$. These formulations are relatively safer ${ }^{7}$. Medicinal plants also have the advantages of being cheaper and more readily available.

Acalypha wilkesiana Mull Arg 'Inferno' (family Euphorbiaceae) is an ornamental plant grown as a hedge. It is commonly called the copperleaf and is widely distributed in the tropics. Few pharmacological and phytochemical assessments have been done on the species. According to Larbie et al. ${ }^{8}$, the hydroethanolic extract of the plant contains triterpenoids, alkaloids, flavonoids, glycosides, coumarins, sterols, and hydrolysable tannins. The study also revealed high antioxidant and significant bactericidal activities of A. wilkesiana. The species has also been demonstrated to improve the clearance of glucose and is toxicologically safe in animals ${ }^{9,10}$. A recent study also demonstrated the nephroprotective activity of the plant in gentamicin- and cisplatin-induced nephrotoxicity $^{11}$, while the $250 \mathrm{mg} / \mathrm{kg}$ dose was demonstrated to possess the highest acute hepatoprotective activity $^{12}$. Furthermore, the protective effect of aqueous leaf extracts of A. wilkesiana 'Godseffiana', a related cultivar, has been reported ${ }^{13}$. The present study, thus, sought to investigate the subacute hepatoprotective effects of $A$. wilkesiana against $\mathrm{CCl}_{4}$-induced toxicity in animals based on biochemical and histological assessment, non-invasive anti-fibrotic evaluation, and inflammation.

\section{MATERIALS - METHODS}

\section{Drugs and chemicals}

Formalin, ethylene diamine tetraacetic acid (EDTA), and sodium dihydrogen phosphate were obtained from Sigma (St. Louis, MO), and Silymarin (Legalon 70, Bukwang Param, Seoul, Korea). Assay kits for biochemical parameters were obtained from ELITECH (Paris, France). All reagents and solvents were of analytical grade.

\section{Animals}

The animals used in the study, Sprague-Dawley rats (14-week old males, 170-230 $\mathrm{g}$ in weight), were obtained from the University of Ghana Medical School, Korle-Bu, Ghana and maintained in the animal holding facility of the Department of Biochemistry and Biotechnology, KNUST, Kumasi. They were kept in metal cages comfortably bedded with wood shavings and at a constant temperature of $22-25^{\circ} \mathrm{C}$, with $12 \mathrm{~h}$ light and $12 \mathrm{~h}$ dark cycle. The animals had free access to standard feed (Mash, AGRICARE, Kumasi-Ghana) and tap water ad libitum except in an overnight fast before the first treatment and sacrifice. In the experimental grouping of the animals, their body weights were taken into consideration to achieve approximately equal conditions among the groups. The animals were given color codes on their tails using permanent markers for easy identification. All animals were humanely handled during the experiment and conducted following the guidelines of the Committee for the Purpose of Control and Supervision of Experiment on Animals (CPCSEA, New Delhi, India) and the National Research Council's Guide for Care and Use of Laboratory Animals ${ }^{14}$. The study protocol was reviewed and approved by a veterinarian on the research team.

\section{Plant preparation and extraction}

A. wilkesiana leaves were collected and prepared as previously described ${ }^{8-10}$. Briefly, the leaves were identified as A. wilkesiana inferno, previously described as $A$. inferno (voucher number KNUST/HM/2017/L018), air-dried under shade, and milled. The $50 \%$ hydroethanolic extract was prepared (100 g in $1000 \mathrm{ml}$, repeated twice), concentrated (at $45^{\circ} \mathrm{C}$ under pressure using Buchi R205, Switzerland), freeze-dried (Labconco, England), and designated as the hydroethanolic extract of A. wilkesiana (AWE, yield of $11.5 \%$ ). 


\section{Experimental design}

Subacute liver injury was achieved in animals by a slightly modified method of Tipoe et al. ${ }^{15}$. The animals were sorted into four groups $(\mathrm{n}=5)$ : Group 1 , the control group was given the vehicle $(1 \mathrm{ml}$ distilled water and $1 \mathrm{ml} / \mathrm{kg}$ b.wt. olive oil on respective days of $\mathrm{CCl}_{4}$ administration); Group 2 was given $1 \mathrm{ml} / \mathrm{kg}$ of $\mathrm{CCl}_{4}$ (1: $1 \mathrm{v} / \mathrm{v}$ in olive oil, ip); Group 3 was administered with $\mathrm{CCl}_{4}+$ Silymarin $(120 \mathrm{mg} / \mathrm{kg}$ in normal saline by oral route); and Group 4 was administered with $\mathrm{CCl}_{4}+\mathrm{AWE}(250 \mathrm{mg} / \mathrm{kg}$ in normal saline by the oral route which was previously determined to be a safe dose with hepatoprotective activity) ${ }^{9,15}$. The $\mathrm{CCl}_{4}$ alone was administered twice a week (every Wednesday and Friday) for 8 weeks. Silymarin and AWE were administered once daily throughout the entire duration of the experiment. Rats were anesthetized and sacrificed at the end of the 8 weeks after an overnight fast.

\section{Effect of treatment on hematology and bio- chemical parameters}

At termination, animals were fasted overnight and exposed to light ether anesthetization. Incisions were then made at the cervical regions using a sterile blade and blood collected into EDTA tubes for hematology analyses using the Sysmex Hematology System (USA). The following parameters were assayed: hemoglobin concentration (HGB), red blood cell (RBC) count, red cell indices [mean corpuscular volume (MCV), mean corpuscular hemoglobin $(\mathrm{MCH})$, mean corpuscular hemoglobin concentration (MCHC), and red cell distribution width (RDW)], platelet count, white blood cells (WBC), lymphocytes, hematocrit, plateletcrit, platelet distribution width (PDW), and platelet large cell ratio (P-LCR).

Part of the blood was collected into gel-activated tubes, allowed to clot, and centrifuged at $3500 \mathrm{rpm}$ for 10 minutes. The serum obtained was analyzed for liver function parameters [i.e. alanine aminotransferase (ALT), aspartate aminotransferase (AST), alkaline phosphatase (ALP), and bilirubin (total, direct and indirect)], lipids [total cholesterol (TChol), triglycerides (Trig), very low-density lipoproteins (VLDL), and high-density lipoproteins (HDL)], and alpha-fetoprotein using the Selectra E (Vital Scientific, Japan) and reagents from ELITECH (France).

The animals were dissected, and the livers were removed, cleared of fat, washed with normal buffered saline and blotted to dry. They were weighed to obtain the absolute liver weight (ALW). The relative liver weight (RLW) was calculated as a function of the body weight at sacrifice.

\section{Histology and liver antioxidant assays}

A tissue section of the liver (right lobe) was stored in $10 \%$ buffered formalin and processed for histological assessment using standard methods. The specimens were stained with hematoxylin and eosin. Photomicrographs were taken and analyzed by a pathologist. Part of the liver was stored in phosphatebuffered saline (PBS) and $5 \mathrm{~g}$ was homogenized separately in $10 \mathrm{ml}$ of $100 \mathrm{mM} \mathrm{KH}_{2} \mathrm{PO}_{4}$ buffer containing $1 \mathrm{mM}$ EDTA ( $\mathrm{pH} 7.4$ ), and centrifuged at 12,000 rpm for $30 \mathrm{~min}$ at $4^{\circ} \mathrm{C}$. The supernatant was collected and used for liver pro- and anti-oxidant parameters, including total protein, superoxide dismutase $(\mathrm{SOD})^{16}$, malondialdehyde (MDA) ${ }^{17}$, reduced glutathione $(\mathrm{GSH})^{18}$, glutathione peroxidase $(\mathrm{GPx})^{19}$, and glutathione transferase (GST) ${ }^{20}$.

\section{Immunohistochemical analysis}

The immunohistochemical staining was performed using the Streptavidin-biotin peroxidase complex kit (M IHC Select Detection System, HRP/DAB, Merck, Germany LOT: 2775482) with a slight modification of the procedure, as previously described by Jarikre and Emikpe $^{21}$ and previously used ${ }^{22}$. Rabbit monoclonal to NF-kB (2A12A7), COX-1 (19999, Lot \# L1113), IL17 (SAB3701439, Lot R127357), and IL-23 (Cat. \# 061079, Lot \# 2914943) were used as primary antibodies. Goat Anti-Rabbit IgG (HRP, ab6721) was used as the secondary antibody. Tissue sections from the control rats served as negative controls. The photomicrographs were taken with the aid of a digital camera (Amscope MU900) attached to the microscope. The images were quantified for staining intensity using the reciprocal intensity of the stained markers on the open-source Fiji (ImageJ) software. The optical density of the staining intensities was calculated using the formula:

$$
O D=\log 10 \frac{\text { Maximum Reciprocal Intensity }}{\text { Mean Reciprocal Intensity }}
$$

\section{Data analysis}

Results were analyzed with GraphPad Prism 7 (GraphPad Software Inc., La Jolla, CA, USA). The results (body weights, hematological parameters, serum biochemistry, and antioxidants) were recorded as mean \pm standard error of mean (SEM). Data were subjected to one-way ANOVA and Tukey's multiple comparison test at a significance value of $5 \%$. Indices of fibrosity including AST/ALT, aspartate aminotransferase to platelet ratio index (APRI), and AST/PLT ratios were calculated. 


\section{RESULTS}

\section{Effect of treatment on liver weight}

Figure 1 shows the effect of treatment on the absolute and relative liver weights. $\mathrm{CCl}_{4}$ and AWE treatment resulted in significant increases in absolute but not relative liver weight.

\section{Effect of treatment on some hematological parameters}

Table 1 shows the effect of treament on some hematological parameters of animals. Treatment had no significant effect on the haematological parameters, except for a decrease in platelet (PLT) levels in $\mathrm{CCl}_{4}$ only treated group $(\mathrm{p}<0.05)$. AWE and Silymarin treatment restored PLT levels to near normal.

\section{Effect of treatment on serum biochemical parameters and liver oxidative stress status}

Table 2 shows the effect of treatment on the biochemical and antioxidant profiles of animals. $\mathrm{CCl}_{4}$ treatment resulted in significant increases in ALT, AST, ALP and bilirubin levels. Silymarin and AWE treatment resulted in decreases in these functions to nearnormal levels. No significant changes were observed for the pro- and anti-oxidant status of the liver, except for an increase in the levels of reduced GSH in Silymarin co-treated group.

\section{Effect of treatment on some indices of liver fibrosis}

Table 3 shows the effect of the treatment on some non-invasive indices of liver fibrosis. $\mathrm{CCl}_{4}$ resulted in significant increases in AFP and AST/PLT ratio and decreases in AST/ALT ratio and APRI. Silymarin and AWE prevented fibrosis based on observations with AFP. APRI was significantly lower in the Silymarin group compared with $\mathrm{CCl}_{4}$-only group, while the AST/PLT ratio was reduced in the AWE group.

\section{Effect of Treatment on Liver Histology}

Figure 2(A-D) shows representative liver sections of normal and treated groups. $\mathrm{CCl}_{4}$ treatment resulted in severe hepatocellular vacuolar degenerations with extensive coagulation necrosis of hepatocytes, inflammation, and fibroblast proliferation (Figure 2B). Silymarin and AWE treatment reversed these injuries to near normal architecture, especially as it relates to the necrosis of hepatocytes, as there were a few regenerative hepatocytes.

\section{Effect of treatment on expression of pro-} inflammatory cytokines

Figure 3 shows the micrograph of liver sections of normal and treated groups for the expression of interleukin (IL)-17 and 23, nuclear factor kappa-lightchain-enhancer of activated $B$ cells (NF-kB) and cyclooxygenase-1 (COX-1). Figure 4 shows the percent intensity of the expression of the cytokines. $\mathrm{CCl}_{4}$ treatment resulted in the overexpression of these cytokines while AWE treatment suppressed these to near-normal levels.

\section{DISCUSSION}

Liver damage is associated with a significant increase in the serum levels of some enzymes which are normally segregated in the parenchymal cells of the liver. Examples of these enzymes include AST, ALP and $\mathrm{ALT}^{3} \cdot \mathrm{CCl}_{4}$ administration increased the serum levels of the aforementioned enzymes, indicative of liver damage. $\mathrm{CCl}_{4}$, an intrinsic liver toxin, is known to mediate its toxic activity by the generation of free radicals and induction of oxidative stress ${ }^{5}$. Once metabolized, $\mathrm{CCl}_{4}$ results in primary and secondary bond formation (a covalent bond formation with DNA, proteins, lipids, and carbohydrates), which results in cell damage. Damage to the hepatocytes then leads to the leakage of these enzymes into the serum ${ }^{6}$. Previous studies revealed the presence of flavonoids and hydrolysable tannins in the hydroethanolic extracts of A. wilkesiana, and these possess high antioxidant activity $^{8}$. This explains the observed decrease in the ALT, AST and ALP levels upon administration of $\mathrm{CCl}_{4}$ and AWE. In the case of AST and ALP, the levels were near normal.

Consistent with results from a previous study, administration of $1 \mathrm{ml} / \mathrm{kg}$ b.wt. $\mathrm{CCl}_{4}$ intraperitoneally for 8 weeks resulted in a marked increase in the serum bilirubin levels (direct and indirect) and a decrease in total cholesterol and triglyceride levels ${ }^{23}$. This is indicative of liver damage. However, administration of plant extract did not have any significant effect on the serum cholesterol and triglyceride levels.

There is a common association between hepatic fibrosis and oxidative stress. Free radicals result in peroxidation of membrane lipids, thereby leading to cell damage. Thus, antioxidants may help in reducing the progression of liver fibrosis ${ }^{24}$. Results from this study showed no significant effects of $\mathrm{CCl}_{4}$ on MDA levels; however, there was some decrease in the GSH levels. Decreased GSH levels upon $\mathrm{CCl}_{4}$ administration was also observed in the previous studies ${ }^{25}$. High antioxidant activity evident by high concentrations of 


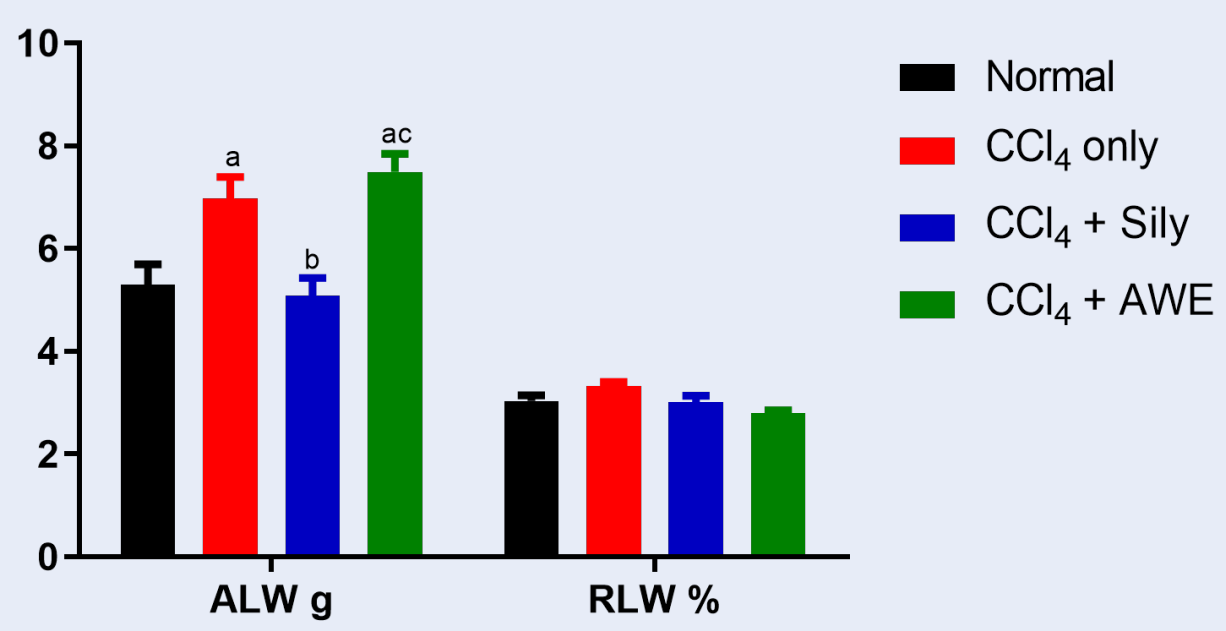

Organ Weight

Figure 1: Effect of treatment on absolute and relative liver weights. Each bar is a mean $\pm \mathbf{S E M}$ of $\mathbf{5}$ animals. Statistical difference: ${ }^{a}$ : different from Normal at $\mathrm{p}<0.05-0.001 ;{ }^{b}$ : different from $\mathrm{CCl}_{4}$ only at $\mathrm{p}<0.05-0.001{ }^{c}{ }^{c}$ : different from $\mathrm{CCl}_{4}+$ Sily at $\mathrm{p}<0.05-0.001$

Table 1: Effect of treatment on some haematological parameters

\begin{tabular}{|c|c|c|c|c|}
\hline Parameters & Normal & $\mathrm{CCl}_{4}$ only & $\mathrm{CCl}_{4}+$ Sily & $\mathrm{CCl}_{4}+\mathrm{AWE}$ \\
\hline $\mathrm{WBC}(\mathrm{x} 1000 / \mu \mathrm{L})$ & $10.30 \pm 1.04$ & $12.30 \pm 1.55$ & $8.48 \pm 0.62$ & $9.10 \pm 0.79$ \\
\hline $\mathrm{RBC}\left(\mathrm{x} 10^{6} / \mu \mathrm{L}\right)$ & $8.61 \pm 0.19$ & $8.96 \pm 0.14$ & $8.62 \pm 0.21$ & $8.56 \pm 0.23$ \\
\hline HGB (g/dL) & $14.60 \pm 0.26$ & $15.78 \pm 0.23$ & $14.58 \pm 0.34$ & $14.75 \pm 0.15$ \\
\hline HCT (\%) & $51.27 \pm 0.64$ & $54.43 \pm 1.27$ & $51.10 \pm 1.28$ & $51.85 \pm 1.19$ \\
\hline MCV (fL) & $59.53 \pm 0.73$ & $60.75 \pm 0.70$ & $59.33 \pm 1.09$ & $60.60 \pm 0.58$ \\
\hline $\mathrm{MCH}(\mathrm{pg})$ & $16.93 \pm 0.23$ & $17.60 \pm 0.10$ & $16.93 \pm 0.19$ & $17.28 \pm 0.43$ \\
\hline $\mathrm{MCHC}(\mathrm{g} / \mathrm{dL})$ & $28.47 \pm 0.18$ & $29.00 \pm 0.28$ & $28.50 \pm 0.19$ & $28.48 \pm 0.54$ \\
\hline $\operatorname{PLT}\left(\mathrm{x} 10^{3} / \mu \mathrm{L}\right)$ & $887.67 \pm 34.17$ & $732.50 \pm 58.35^{a}$ & $884.00 \pm 30.48^{b}$ & $832.50 \pm 72.66^{b}$ \\
\hline LYM (\%) & $78.50 \pm 6.26$ & $73.43 \pm 5.78$ & $72.35 \pm 1.52$ & $64.28 \pm 7.14$ \\
\hline NEUT (\%) & $21.50 \pm 6.26$ & $26.58 \pm 5.78$ & $27.65 \pm 1.52$ & $32.75 \pm 6.55$ \\
\hline $\operatorname{LYM}\left(\mathrm{x} 10^{3} / \mu \mathrm{L}\right)$ & $8.17 \pm 1.37$ & $9.13 \pm 1.55$ & $6.15 \pm 0.51$ & $5.80 \pm 0.71$ \\
\hline $\operatorname{NEUT}\left(\mathrm{x} 10^{3} / \mu \mathrm{L}\right)$ & $2.13 \pm 0.62$ & $3.18 \pm 0.56$ & $2.33 \pm 0.16$ & $3.08 \pm 0.75$ \\
\hline RDW-SD (fL) & $31.37 \pm 0.44$ & $32.00 \pm 0.67$ & $31.30 \pm 0.47$ & $32.58 \pm 0.71$ \\
\hline RDW-CV (\%) & $13.00 \pm 0.44$ & $13.00 \pm 0.30$ & $13.33 \pm 0.50$ & $14.65 \pm 0.42$ \\
\hline PDW (fL) & $7.33 \pm 0.03$ & $7.95 \pm 0.23$ & $7.85 \pm 0.13$ & $8.25 \pm 0.73$ \\
\hline MPV (fL) & $6.53 \pm 0.03$ & $6.95 \pm 0.13$ & $6.80 \pm 0.07$ & $7.10 \pm 0.40$ \\
\hline P-LCR (\%) & $4.30 \pm 0.32$ & $5.95 \pm 0.51$ & $5.35 \pm 0.27$ & $7.35 \pm 2.46$ \\
\hline PCT (\%) & $0.58 \pm 0.02$ & $0.62 \pm 0.03$ & $0.50 \pm 0.03$ & $0.59 \pm 0.05$ \\
\hline
\end{tabular}

Statistical difference: a: different from Normal at $\mathrm{p}<0.05-0.001$; b: different from $\mathrm{CCl}_{4}$ only at $\mathrm{p}<0.05-0.001$. 
Table 2: Effect of treatment on serum biochemistry and liver antioxidant parameters

\begin{tabular}{|c|c|c|c|c|}
\hline & Normal & $\mathrm{CCl}_{4}$ & $\mathrm{CCl}_{4}+$ Sily & $\mathrm{CCl}_{4}+\mathrm{AWE}$ \\
\hline \multicolumn{5}{|c|}{ Liver Function Parameters } \\
\hline $\operatorname{ALT}(\mathrm{U} / \mathrm{L})$ & $117.70 \pm 11.65$ & $566.68 \pm 46.58^{a}$ & $154.05 \pm 22.70^{b}$ & $330.18 \pm 20.19^{a b c}$ \\
\hline AST (U/L) & $396.35 \pm 38.00$ & $463.98 \pm 21.83$ & $327.35 \pm 21.04^{b}$ & $326.18 \pm 20.89^{b}$ \\
\hline $\operatorname{ALP}(\mathrm{U} / \mathrm{L})$ & $160.15 \pm 12.92$ & $230.45 \pm 33.43$ & $311.73 \pm 23.33^{a}$ & $180.05 \pm 18.44^{c}$ \\
\hline TBil $(\mu \mathrm{mol} / \mathrm{L})$ & $3.84 \pm 0.35$ & $6.86 \pm 1.24^{a}$ & $5.78 \pm 0.63$ & $4.81 \pm 0.51$ \\
\hline $\operatorname{DBil}(\mu \mathrm{mol} / \mathrm{L})$ & $1.99 \pm 0.27$ & $3.20 \pm 1.21^{a}$ & $2.30 \pm 0.33$ & $2.21 \pm 0.30$ \\
\hline $\operatorname{IBil}(\mu \mathrm{mol} / \mathrm{L})$ & $2.27 \pm 0.25$ & $3.08 \pm 0.69$ & $3.18 \pm 0.08$ & $2.42 \pm 0.44$ \\
\hline \multicolumn{5}{|l|}{ Lipids Profile } \\
\hline TChol (mmol/L) & $2.32 \pm 0.25$ & $1.79 \pm 0.17^{a}$ & $2.07 \pm 0.38^{b}$ & $1.41 \pm 0.12^{a}$ \\
\hline TRIGs (mmol/L) & $2.42 \pm 0.47$ & $1.62 \pm 0.27^{a}$ & $1.34 \pm 0.24^{a}$ & $1.35 \pm 0.24^{a}$ \\
\hline $\begin{array}{l}\text { VLDL-Chol } \\
(\mathrm{mmol} / \mathrm{L})\end{array}$ & $1.13 \pm 0.23$ & $0.70 \pm 0.07^{a}$ & $0.58 \pm 0.10^{a}$ & $0.63 \pm 0.11^{a}$ \\
\hline HDL-Chol (mmol/L) & $0.73 \pm 0.14$ & $0.46 \pm 0.03^{a}$ & $0.54 \pm 0.13^{a}$ & $0.50 \pm 0.07^{a}$ \\
\hline \multicolumn{5}{|l|}{ Oxidative Stress } \\
\hline $\mathrm{TP}(\mathrm{mg} / \mathrm{dL})$ & $0.97 \pm 0.09$ & $1.02 \pm 0.05$ & $0.96 \pm 0.08$ & $0.98 \pm 0.09$ \\
\hline MDA (mM/mg prot) & $0.79 \pm 0.11$ & $0.77 \pm 0.09$ & $0.76 \pm 0.07$ & $0.74 \pm 0.11$ \\
\hline GPx (U/mg prot) & $35.63 \pm 0.90$ & $38.57 \pm 4.01$ & $36.47 \pm 1.64$ & $34.13 \pm 1.14$ \\
\hline GSH (mM/mg prot) & $169.48 \pm 15.78$ & $157.99 \pm 7.11$ & $186.06 \pm 15.69^{b}$ & $164.91 \pm 15.10$ \\
\hline GST (mM/mg prot) & $1.78 \pm 0.34$ & $3.43 \pm 0.41$ & $3.29 \pm 0.45$ & $3.94 \pm 0.57$ \\
\hline SOD (U/mg prot) & $7.89 \pm 0.53$ & $7.34 \pm 0.33$ & $8.25 \pm 0.74$ & $7.97 \pm 0.71$ \\
\hline
\end{tabular}

Statistical difference: a: different from Normal at $\mathrm{p}<0.05-0.001$; b: different from $\mathrm{CCl}_{4}$ only at $\mathrm{p}<0.05-0.001$.

Table 3: Effect of treatment on some indices of liver fibrosis

\begin{tabular}{lcccc}
\hline & Normal & $\mathbf{C C l}_{4}$ & $\mathbf{C C l}_{\mathbf{4}}+\mathbf{S i l y}$ & $\mathbf{C C l}_{\mathbf{4}}+\mathbf{A W E}$ \\
\hline AFP (ng/mL) & $3.85 \pm 0.15$ & $5.29 \pm 0.07^{a}$ & $4.72 \pm 0.33$ & $4.17 \pm 0.32$ \\
AST/ALT & $3.67 \pm 0.64$ & $0.83 \pm 0.07^{a}$ & $2.27 \pm 0.36^{a b}$ & $0.99 \pm 0.06^{a}$ \\
APRI (\%) & $0.09 \pm 0.01$ & $0.13 \pm 0.01^{a}$ & $0.076 \pm 0.01^{b}$ & $0.08 \pm 0.01^{b}$ \\
AST/PLT Ratio & $44.86 \pm 4.31$ & $64.63 \pm 6.35^{a}$ & $45.82 \pm 5.64^{b}$ & $40.69 \pm 6.12^{b}$ \\
\hline
\end{tabular}

Statistical difference: a: different from Normal at $\mathrm{p}<0.05-0.001$; b: different from $\mathrm{CCl}_{4}$ only at $\mathrm{p}<0.05-0.001$.

flavonoids and tannins in the hydroethanolic extract of $A$. wilkesiana ${ }^{8}$ explains the increase in GSH levels in the $\mathrm{CCl}_{4}+\mathrm{AWE}$ group. The increase was, however, very prominent in the Silymarin-treated group, confirming the high degree of hepatoprotection.

Biopsy of the liver remains the ultimate technique for assessing hepatopathies ${ }^{26}$, such as for example, detecting and determining the stage of fibrosis in nonalcoholic steatohepatitis ${ }^{27}$. The procedure is invasive, however, and has risks of serious complications. Other cost-effective and useful means that are easy to measure and handle include platelet count, AST/ALT ratio, AST-to-platelet ratio index (or APRI), etc. ${ }^{26} \mathrm{An}$ increase in the APRI was seen in the $\mathrm{CCl}_{4}$ control group. Administration of Silymarin and AWE resulted in a decrease in the APRI. Blood platelet levels and AST levels are known to decrease and increase respectively with fibrosis progression ${ }^{26}$. Thus, an increase in APRI is shown to be an index of the severity of hepatic disease ${ }^{28}$, even in animal models. Though the APRI alone is likely not sufficiently sensitive to rule out significant disease, the lower the 

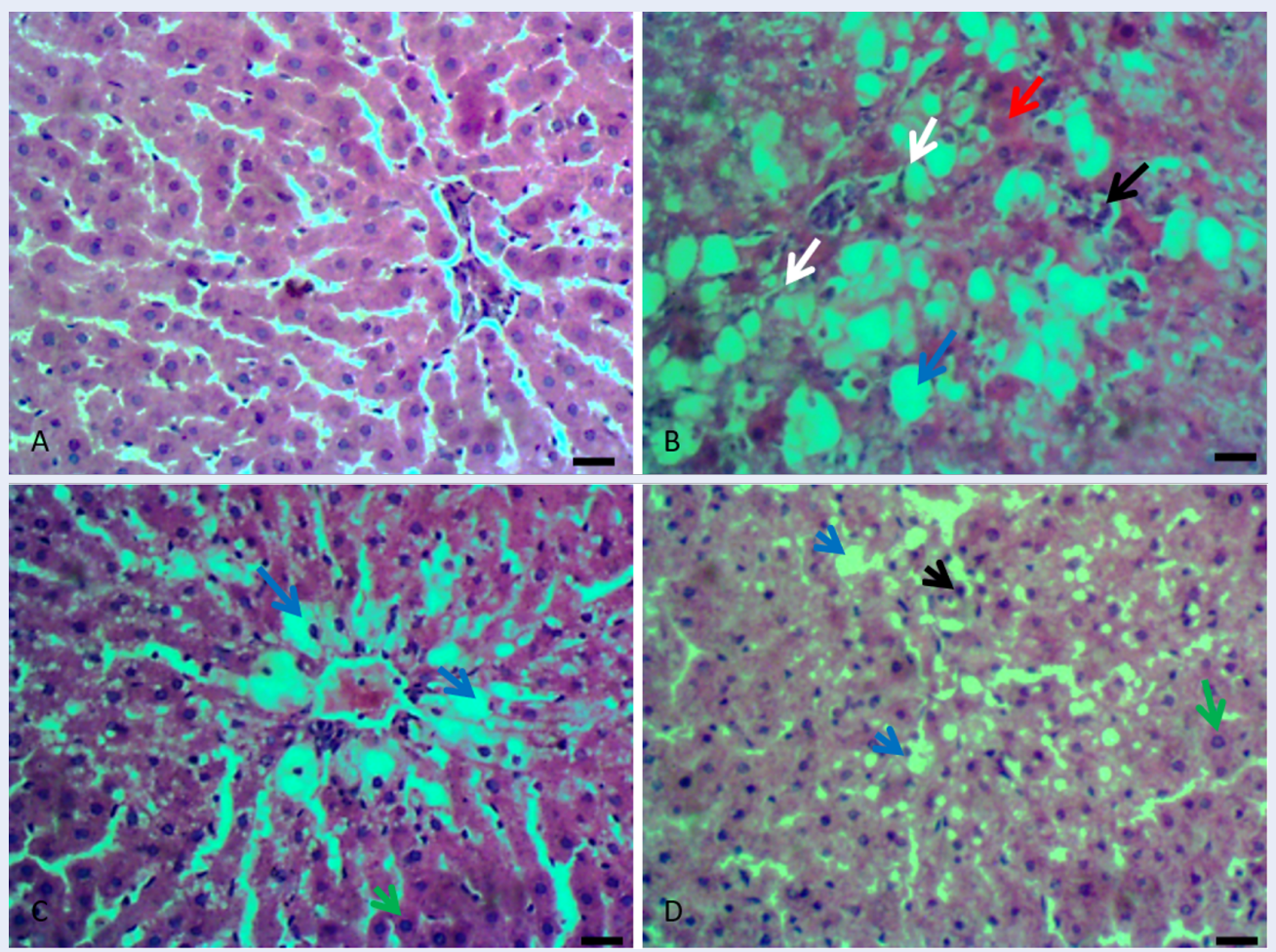

Figure 2: Micrographs of liver sections of normal and treated rats. (A) Normal group showing no observable lesion. (B) $\mathrm{CCl}_{4}$ only showing bridging hepatocellular vacuolar degeneration (blue arrow), spotty necrosis (red arrow) within flammation (black arrow) and fibroblasts response (white arrow). (C) $\mathrm{CCl}_{4}+$ Sily showing moderate centrilobular hepatocellular vacuolar degeneration (blue arrows) and regenerative hepatocytes (green arrows). (D) $\mathrm{CCl}_{4}+250 \mathrm{mg} / \mathrm{kg}$ AWE showing moderate centrilobular vesicular hepatocellular degeneration (blue arrows), regenerative hepatocytes (green arrows) and Kupffer cell hyperplasia (black arrow) (HE stain, X400; scale bar = 20 $\mu \mathrm{m})$

APRI score (less than 0.5), the greater the negative predictive value (and ability to rule out cirrhosis); the higher the value (greater than 1.5), the greater the positive predictive value (and ability to rule in cirrhosis) ${ }^{29} \cdot \mathrm{CCl}_{4}$ was, therefore, confirmed to have caused hepatotoxicity, which was reversed in the AWE and Silymarin-treated groups.

The current study showed that Silymarin and AWE improved PLT levels compared with $\mathrm{CCl}_{4}$-only group. Cirrhotic rats induced with dimethylnitrosamine and $70 \%$ hepatectomy were demonstrated to have improved platelet levels by a single intravenous injection of thrombopoietin which correlated with the inhibition of HSC activation and decrease of the fibrotic area in the liver, while antiplatelet serum attenuated hepatic regeneration ${ }^{30}$. It has been suggested that platelets may promote hepatocyte proliferation by secreting hepatocyte growth factor (HGF), a potent mitogen for hepatocytes. HGF is known to activate MET receptor essential for organogenesis and wound healing. Further, HGF may contribute to the resolution of fibrosis by modulating levels of TGF- $\beta$ and matrix metalloproteinases (MMPs), which are the main ECM enzymes degrading collagen ${ }^{31}$. Platelets are known to induce hepatic regeneration by directly interacting with hepatocytes by promoting cell cycle progression and metabolic pathways in hepatocytes ${ }^{32}$.

Furthermore, as mentioned earlier, AWE and Silymarin treatments restored the histology of the liver after $\mathrm{CCl}_{4}$ damage to near normal architecture. Also, the high expression of IL-17, IL-23, NF- $\kappa \mathrm{B}$ and COX-2 in the $\mathrm{CCl}_{4}$ treated group shows the necrotic and inflammatory reactions in $\mathrm{CCl}_{4}$-induced toxicity. NF- $\kappa \mathrm{B}$ and COX-1 as pro-inflammatory signals and their roles in liver fibrosis have been well established $^{33,34}$. IL-17 has been shown to directly promote the production of IL- 6 and IL- 8 in human dermal fibroblasts ${ }^{35}$ with in vitro studies showing an increased proliferation of fibroblasts in vascular endothelial cells, suggesting the pivotal role of IL-17 in fibrosis and endothelial inflammation ${ }^{36,37}$. IL-17 is 


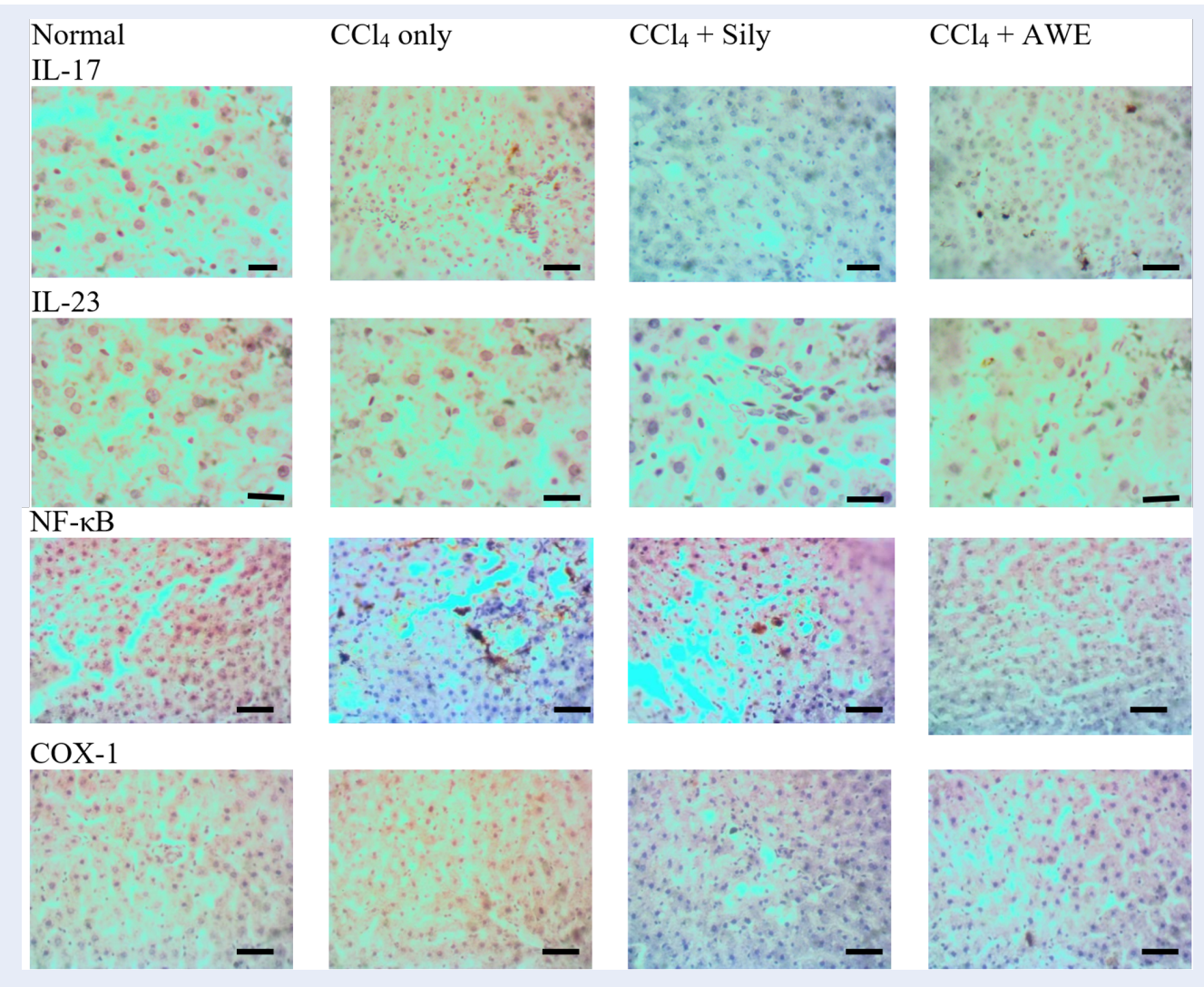

Figure 3: Effect of treatment on the expression of IL-17, IL-23, NF- $\kappa$ B and COX-1 in liver cells. Streptavidinbiotin complex Horseradish immunoperoxidase with Haematoxylin counterstain ( $x 400$; scale bar $=20 \mu \mathrm{m}$ )

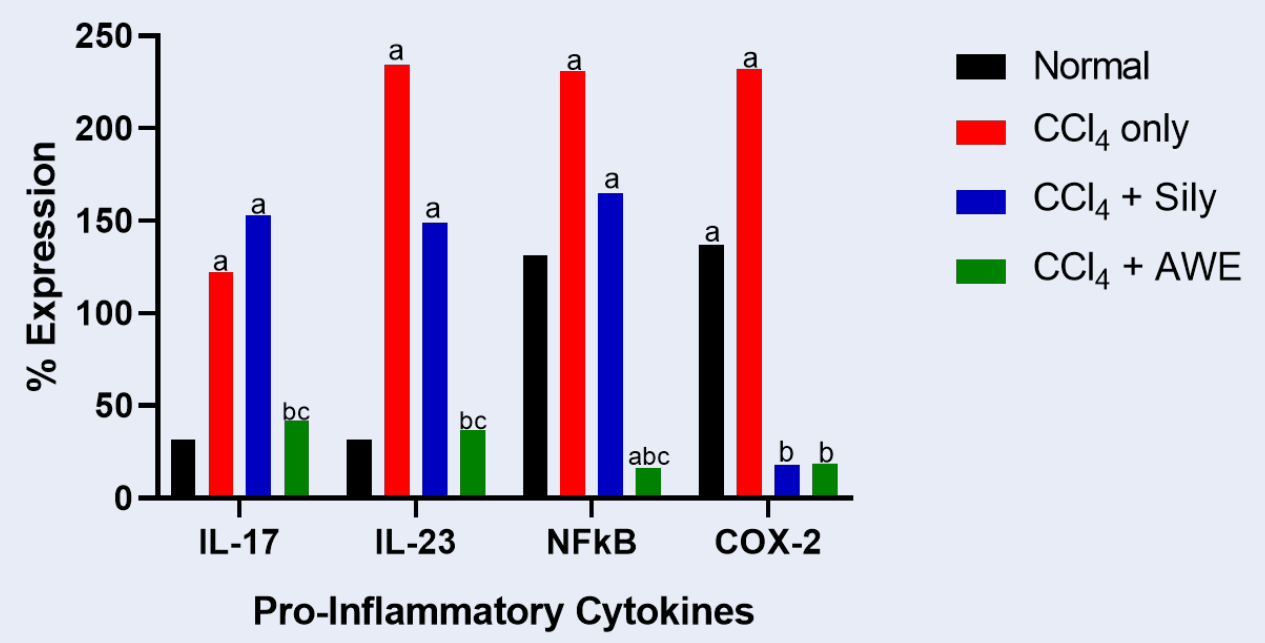

Figure 4: Effect of treatment on percent expression of IL-17, IL-23, NF- $\kappa$ B and COX-1. $\mathrm{CCl}_{4}$ treatment included over-expression of pro-inflammatory cytokines while Silymarin and AWE down-regulated these to near-normal levels. Each bar is a mean of 5 animals. Statistical difference: ${ }^{a}$ : different from Normal at $p<0.05-0.001$; ${ }^{\mathbf{b}}$ : different from $\mathrm{CCl}_{4}$ only at $\mathrm{p}<0.05-0.001 ;^{c}$ : different from $\mathrm{CCl}_{4}+$ Sily at $\mathrm{p}<0.05-0.001$. 
a major pro-inflammatory cytokine involved in neutrophil recruitment ${ }^{38}$. IL-23 is a pro-inflammatory heterodimeric cytokine composed of an IL12B (IL12p40) subunit (that is shared with IL12) and the IL23A (IL-23p19) subunit ${ }^{39}$. In psoriasis, IL-23 expression is markedly upregulated, compared to normal skin ${ }^{40}$, and also in chronic bowel inflammation ${ }^{41}$. Thus both IL-17 and 23 are significantly involved in inflammation, leading to fibrosis. In the current study, AWE was observed to significantly downregulate the expression of these proinflammatory molecules, underscoring the healing properties of the extract.

It can be suggested that the subchronic protective effect of A. wilkesiana 'inferno' leaf extracts on the liver of animals against $\mathrm{CCl}_{4}$-induced toxicty is by protecting tissues membranes from peroxidation, leakage of enzymes, and improvement of the microstructure. Also, the extracts protect against the overexpression of pro-inflammatory cytokines and related activities leading to cell death.

\section{CONCLUSION}

This study indicates that Acalypha wilkesiana 'inferno' possesses subacute protection against $\mathrm{CCl}_{4}$-induced toxicity by reducing the levels of ALT, ALP and AST, as well as AFP, AST/PLT ratio and APRI. The protective effect of this extract was supported by histological and immunohistochemistry observations. Thus, 50\% hydroethanolic extract of $A$. wilkesiana inferno can be developed as an effective hepatoprotective agent which brings about the functional improvement of liver function and can be exploited as a therapeutic agent against liver fibrosis.

\section{ABBREVIATIONS}

$\alpha$-SMA: alpha-smooth muscle actin

AFP: alpha-fetoprotein

ALP: alkaline phosphatase

ALT: alanine aminotransferase

ALW: absolute liver weight

APRI: aspartate aminotransferase to platelet ratio index

AST: aspartate aminotransferase

AWE: Acalypha wilkesiana hydroethanolic extract

$\mathbf{C C l}_{4}$ : Carbon tetrachloride

COX-1: clyclooxygenase-1

DBil: direct bilirubin

DNA: deoxyribonucleic acid

GPx: glutathione peroxidase

GSH: reduced glutathione

GST: glutathione transferase

HCT: haematocrit
HDL: high density lipoproteins

HGB: haemoglobin concentration

HSC: hepatic stellate cells

IBil: indirect bilirubin

IL-17: interleukin-17

IL-23: interleukin-23

LYM: lymphocytes

MCH: mean corpuscular haemoglobin

MCHC: mean corpuscular haemoglobin concentration

MCV: mean corpuscular volume

MDA: malondialdehyde

mRNA: messenger ribonucleic

$\mathrm{Nfk} \beta$ : nuclear factor kappa B

PCT: Plateletcrit

PDW: platelet distribution width

P-LCR: platelet larger cell ratio

PLT: platelet

RBC: red blood cell

RDW: red cell distribution width

RLW: relative liver weight

SOD: superoxide dismutase

TBil: total bilirubin

TChol: total cholesterol

TGF- $\beta$ : tumour growth factor- $\beta$

Trig: triglycerides

VLDL: very low density lipoproteins

WBC: white blood cell

WHO: world health organization

\section{ACKNOWLEDGMENTS}

Not applicable.

\section{AUTHOR'S CONTRIBUTIONS}

C. Larbie conceived and designed the experiments; analyzed and interpreted the biochemical and hematological data; BO Emikpe and T.A. Jarikre contributed reagents and performed all histology and immunohistochemical experiments; A.A. Oyagbemi contributed reagents and performed all liver antioxidant experiments; C. Larbie, C. Owusu Adjei, R.A. Nyarko and E.B. Aseidu managed all literature search and drafted the manuscript. All authors approved the final manuscript.

\section{FUNDING}

This research did not receive any specific grant from funding agencies in the public, commercial, or notfor-profit sectors. 


\section{AVAILABILITY OF DATA AND MATERIALS}

Data and materials used and/or analyzed during the current study are available from the corresponding author on reasionable request.

\section{ETHICS APPROVAL AND CONSENT TO PARTICIPATE}

Not applicable.

\section{CONSENT FOR PUBLICATION}

Not applicable.

\section{COMPETING INTERESTS}

The authors declare that they have no competing interests.

\section{REFERENCES}

1. Delgado-Montemayor C, Cordero-Perez P, Salazar-Aranda R Waksman-Minsky N. Models of hepatoprotective activity assessment. Medicina Universitaria;17(69):222-228. Available from: https://doi.org/10.1016/j.rmu.2015.10.002.

2. Bajpai KV, Kim J, Park Y, Kang SC. In vivo pharmacological effectiveness of heat-treated cucumber (Cucumis sativus L.) juice against $\mathrm{CCl} 4$-induced detoxification in a rat model. Indian Journal of Pharmaceutical Education and Research. 2017;51(2):280-287. Available from: https://doi.org/10.5530/ ijper.51.2.33.

3. Budryn G, Zyżelewicz D, Buko V, Lukivskaya O, Naruta E, Belonovskaya $E$, et al. Evaluation of antifibrotic effects of coffee and cocoa extracts in rats with thioacetamideinduced fibrosis. European Food Research and Technology. 2018;244(12):2107-2115. Available from: https://doi.org/10. 1007/s00217-018-3119-z.

4. Rehman A, Waheed A, Tariq R, Zaman M, Tahir MJ. Anti-fibrotic effects of Polygonum plebeium r.br. in CCl4-induced hepatic damage and fibrosis in rats. Biomedical Research and Therapy. 2018;5(4):2223-2234. Available from: https://doi.org/10. 15419/bmrat.v5i4.435.

5. TVSS S, GKP S. Hepatotoxicity Mechanisms and its Biomarkers. International Journal of Pharmaceutical and Chemical Sciences. 2012;1(2):675-682. Available from: https://pdfs.semanticscholar.org/cf58/ c439eadc52cdbe4bcb166f0b43de48709a79.pdf.

6. Weber LWD, Boll M, Stampfl A. Hepatotoxicity and Mechanism of Action of Haloalkanees: Carbon Tetrachloride as a Toxicological Model. Critical Reviews in Toxicity. 2003;33(2):105136. PMID: 12708612 . Available from: https://doi.org/10.1080/ 713611034.

7. Karagoz ID, Ozaslan M, Kilic HI, Guler I, Uyar C, Tuter D, et al. Hepatoprotective effect of diffractaic acid on carbon tetrachloride-induced liver damage in rats. Pharmaceutical Biotechnology. 2015;29(5):1011-1016. Available from: https: //doi.org/10.1080/13102818.2015.1056754.

8. Larbie C, Mills-Robertson FC, Dowuona JNN, Tofah JJ, Torkornoo D, Asare CY. Phytochemical constituents and biological activity of fractions of stem and leaves of Acalypha inferno. Journal of Pharmaceutical Research International. 2017;20(8):1-12. Available from: https://doi.org/10.9734/JPRI/ 2017/38675.

9. Larbie C, Nyarko HN, Tofah JJ, Torkornoo D. Aqueous ethanolic extract of Acalypha inferno leaves is safe in animals. Int J Pharm Scie Res. 2018a;9(6):1000-1008. Available from: 10. 13040/ijpsr.0975-8232.9(6).1000-08.
10. Larbie C, Oduro J, Tofah JJ. Aqueous ethanolic extract of Acalypha inferno accelerates the clearance of glucose in normoglyaecemic rats. The Pharma Innovation. 2018b;7(2):79-83.

11. Larbie C, Emikpe BO, Oyagbemic AA, Jarikre TA, Adjei CO. Extract of Acalypha wilkesiana Mull Arg 'inferno' is nephroprotective in gentamicin and cisplatin-induced kidney damage by inhibition of oxidative stress and inflammation. Under review;

12. Larbie C, Sampson JE, Torkornoo D. Hepatoprotective evaluation of hydroethanolic extract of Acalypha wilkesiana 'inferno' in rats. Under review. 2020;

13. Ikewuchi JC, Uwakwe AA, Eugene N, Onyeike EN, Ikewuchi CC Hepatoprotective effect of an aqueous extract of the leaves of Acalypha wilkesiana 'Godseffiana' Muell Arg (Euphorbiaceae) against carbon tetrachloride induced liver injury in rats. EXCLI J. 2011;10:280-289. Available from: https://doi.org/10.4314/ jasem.v14i3.61454.

14. National Research Council. Guide for care and use of laboratory animal. National Academic Press Washington, Edition 8th. 2011;p. 43-45.

15. Tipoe GL, Leung TM, Liong EC, Lau TY, Fung ML, Nanji AA. Epigallocatechin-3-gallate (EGCG) reduces liver inflammation, oxidative stress and fibrosis in carbon tetrachloride (CCl4)induced liver injury in mice. Toxicology. 2010;273:45-52. PMID: 20438794. Available from: https://doi.org/10.1016/j.tox. 2010.04.014.

16. Oyagbemi AA, Omobowale TO, Akinrinde AS, Saba AB, Ogunpolu BS, Daramola O. Lack of reversal of oxidative damage in renal tissues of lead acetate-treated rats. Environ Toxicol. 2015;30:1235-1243. PMID: 24706517. Available from: https://doi.org/10.1002/tox.21994.

17. Varshney R, Kale RK. Effect of calmodulin antagonists on radiation induced lipid peroxidation in microsomes. Int J Biol. 1990;158:733-741. PMID: 1977818. Available from: https: //doi.org/10.1080/09553009014552121.

18. Jollow DJ, Mitchell JR, Zampaglione N, Gillette JR Bromobenzene-induced liver necrosis. Protective role of glutathione and evidence for 3, 4-bromobenzene oxide as the hepatotoxic metabolite. Pharmacology. 1994;11(3):151-169. PMID: 4831804. Available from: https://doi.org/10.1159/000136485.

19. Beutler E, Duron O, Kelly BM. Improved method for the determination of blood glutathione. J Lab Clin Med. 1963;61:882888. PMID: 13967893.

20. Habig WH, Pabst MJ, Jakoby WB. Glutathione S-Transferases: The first enzymatic step in mercapturic acid formation. J Biol Chem. 1974;249(22):7130-7139. PMID: 4436300.

21. Jarikre TA, Emikpe BO. First report of immunohistochemical detection of Peste des petit ruminants, parainfluenza 3 and respiratory syncytial viral antigens in lungs of Nigerian goats. J Immunoass Immunochem. 2017;38:555-568. PMID: 28679075. Available from: https://doi.org/10.1080/15321819. 2017.1349669.

22. Nyarko RA, Larbie C, Anning AK, Baidoo PK, Emikpe BO, Oyagbemi AA, et al. Griffonia simplicifolia (DC.) Baill. attenuates gentamicin and cisplatin-induced nephrotoxicty in rats. Comparative Clinical Pathology. 2019;p. 1-12. Available from: https://doi.org/10.1007/s00580-019-02934-x.

23. Arthur FKN, Woode E, Terlabi EO, Larbie C. Evaluation of hepatoprotective effect of aqueous extract of Annona muricata (Linn.) leaf against carbon tetrachloride and acetaminopheninduced liver damage. Journal of Natural Pharmaceuticals. 2012;3(1):25-30. Available from: https://doi.org/10.4103/ 2229-5119.96957.

24. Wang L, Cheng D, Wang H, Di L, Zhou X, Xu T, et al. The hepatoprotective and antifibrotic effects of Saururus chinensis against carbon tetrachloride induced hepatic fibrosis in rats. Journal of Ethnopharmacology. 2009;126(3):487-491. PMID 19761824. Available from: https://doi.org/10.1016/j.jep.2009. 09.009 .

25. Gao HY, Li GY, Lou MM, Li XY, Wei XY, Wang JH. Hepatoprotective effect of matrine salvianolic acid $b$ salt on carbon 
tetrachloride-induced hepatic fibrosis. Journal of Inflammation. 2012;9(1):1-9. PMID: 22559721. Available from: https: //doi.org/10.1186/1476-9255-9-16.

26. Wai CT, Greenson JK, Fontana RJ, Kalbfleisch JD, Marrero JA, Conjeevaram HS, et al. A simple noninvasive index can predict both significant fibrosis and cirrhosis in patients with chronic hepatitis C. Hepatology. 2003;38(2):518-526. PMID 12883497. Available from: https://doi.org/10.1053/jhep.2003. 50346.

27. Yoneda $M$, Fujii $H$, Sumida $Y$, Hyogo $H$, Itoh $Y$, Ono $M$, et al Platelet count for predicting fibrosis in nonalcoholic fatty liver disease. Journal of Gastroenterology. 2011;46(11):1300-1306. PMID: 21750883. Available from: https://doi.org/10.1007/ s00535-011-0436-4.

28. Mao W, Sun Q, Fan J, Lin S, Ye B. AST to platelet ratio index predicts mortality in hospitalized patients with hepatitis Brelated decompensated cirrhosis. Medicine (United States). 2016;95(9):1-6. PMID: 26945406. Available from: https://doi. org/10.1097/MD.0000000000002946.

29. Chou R, Wasson N. Blood tests to diagnose fibrosis or cirrhosis in patients with chronic hepatitis $C$ virus infection: a systematic review. Ann Intern Med. 2013;158:807-820. PMID: 23732714. Available from: https://doi.org/10.7326/0003-4819158-11-201306040-00005.

30. Murata S, Hashimoto I, Nakano Y, Myronovych A, Watanabe $M$, Ohkohchi N. Single administration of thrombopoietin prevents progression of liver fibrosis and promotes liver regeneration after partial hepatectomy in cirrhotic rats. Ann Surg. 2008;248:821-828. PMID: 18948810. Available from: https: //doi.org/10.1097/SLA.0b013e31818584c7.

31. Kurokawa T, Ohkohchi N. Platelets in liver disease, cancer and regeneration. World J Gastroenterol. 2017;23(18):3228-3239. PMID: 28566882. Available from: https://doi.org/10.3748/wjg. v23.i18.3228.

32. Myronovych A, Murata S, Chiba M, Matsuo R, Ikeda O, Watanabe $\mathrm{M}$, et al. Role of platelets on liver regeneration after $90 \%$ hepatectomy in mice. J Hepatol. 2008;49:363-372. PMID 18602717. Available from: https://doi.org/10.1016/j.jhep.2008. 04.019.

33. Luedde T, Schwabe RF. NF- $\kappa B$ in the liver-linking injury, fibrosis and hepatocellular carcinoma. Nat Rev Gastroenterol
Hepatol. 2011;8(2):108-118. PMID: 21293511. Available from: https://doi.org/10.1038/nrgastro.2010.213.

34. Martín-Sanz P, Casado M, Boscá L. Cyclooxygenase 2 in liver dysfunction and carcinogenesis: Facts and perspectives. World J Gastroenterol . 2017;23(20):3572-3580. PMID: 28611510. Available from: https://doi.org/10.3748/wjg.v23.i20. 3572 .

35. Fossiez F, Djossou O, Chomarat P, Flores-Romo L, Ait-Yahia S, Maat $C$, et al. T cell interleukin-17 induces stromal cells to produce proinflammatory and hematopoietic cytokines. J Exp Med. 1996;183:2593-2603. PMID: 8676080. Available from: https://doi.org/10.1084/jem.183.6.2593.

36. Kurasawa $K$, Hirose $K$, Sano $H$, Endo $H$, Shinkai $H$, Nawata $\mathrm{Y}$, et al. Increased interleukin-17 production in patients with systemic sclerosis. Arthritis Rheum. 2000;43:2455-2463. PMID: 11083268. Available from: https://doi.org/10.1002/ 1529-0131(200011)43:11<2455::AID-ANR12>3.0.CO;2-K.

37. Xing $X$, Yang J, Yang X, Wei Y, Zhu L, Gao D, et al. IL-17A induces endothelial inflammation in systemic sclerosis via the ERK signaling pathway. PLoS One. 2013;8:e85032. PMID: 24376862 Available from: https://doi.org/10.1371/journal.pone.0085032.

38. Miyamoto M, Prause $O$, Sjostrand M, Laan M, Lotvall J, et al. Endogenous IL-17 as a mediator of neutrophil recruitment caused by endotoxin exposure in mouse airways. J Immunol. 2003;170:4665-4672. PMID: 12707345. Available from: https: //doi.org/10.4049/jimmunol.170.9.4665.

39. Oppmann B, Lesley R, Blom B, Timans JC, Xu Y, Hunte B, et al Novel p19 protein engages IL-12p40 to form a cytokine, IL-23, with biological activities similar as well as distinct from IL-12 Immunity. 2000;13(5):715-725. PMID: 11114383. Available from: https://doi.org/10.1016/S1074-7613(00)00070-4.

40. Hedrick MN, Lonsdorf AS, Shirakawa AK, Lee CCR, Liao F, Singh $\mathrm{SP}$, et al. CCR6 is required for IL-23-induced psoriasis-like infl ammation in mice. J Clin Invest. 2009;119:2317 -2329. PMID 19662682. Available from: https://doi.org/10.1172/JCI37378.

41. Ehlers S, Kaufmann SH. Infection, infl ammation, andchronic diseases: consequences of a modern lifestyle. Trends Immunol. 2010;31:184-190. PMID: 20399709. Available from: https://doi.org/10.1016/j.it.2010.02.003. 